\title{
MINHAS EXPERIÊNCIAS PEDAGÓGICAS NO CURSO DE EDUCAÇÃO INTERCULTURAL/UFG
}

\author{
KARAJÁ ${ }^{1}$, Paulo César Beti \\ Pesquisador da Ação 'Saberes Indígenas na Escola'
}

\section{RYBÈNABUTÈ}

Kaa waõmysỹdỹỹna Ibutuna Hãwa-ki rèwinyre, Tocantins wèrbi roimyhỹre tahè awimy ròhònyre Tema mahãdu-my rarybekre ityrèdi raaõmysỹdỹỹnyre dỹỹraxi rèwinymy Licenciatura Intercultural tyyrtina-ki Universidade Federal tuu riwatohonyre, iwsè tahè rèwinyre dỹỹraxi rbilehè aõ rèlèmyhỹre. Awimy hèka tai rahare kièmy dori irbile bdè rèèryrèri tyyrtidu-my tasỹ tyyrtidỹỹdu-my ãròhònykremy bdèèrymy, kièmy dorihè iwsè rbile tyyrtidu mahãdu iny bdèdỹỹnanarèny aõni tyhymy rierykre inatxi-my bdèèryna, rityhynykre, Iny bdèèryna ta tyyrti rbi bdèèryna.

Rybèna-wèryna: Inymahãdu. Inybdèèryna. Intercultural rbibdèèryna.

\section{RESUMO}

Este trabalho foi realizado na aldeia Ibutuna-Tocantins e foi muito importante no sentido de abordar os temas que foram trabalhados através das pesquisas que a licenciatura intercultural da Universidade Federal de Goiás está desenvolvendo quanto às práticas de pesquisa. Isto porque esta pesquisa foi fundamental na minha formação de professor indígena e, ao mesmo tempo, como aluno também, porque só assim podemos levar o nosso conhecimento para que seja aprofundado na prática pedagógica e em uma educação de qualidade, além de os alunos terem um ensino bilíngue diferenciado. Também refletimos bastante sobre educação indígena e educação escolar indígena.

Palavras-chave: Povo Karajá. Educação Indígena. Educação Intercultural.

1 Rede UFG/UFT/UFMA. Professor de Educação Básica. 


\begin{abstract}
This work was carried out in the Ibutuna-Tocantins village and it was very important in order to approach the themes that were worked through the researches that the intercultural graduation of the Federal University of Goiás is developing regarding the research practices. This is because this research was fundamental in my training as an indigenous teacher and, at the same time, as a student as well, because only then can we bring our knowledge to be deepened in pedagogical practice and in a quality education, besides the students have a different Bilingual education. We also reflected a great deal on indigenous education and indigenous school education.
\end{abstract}

Keywords: Karajá people. Indigenous Education. Intercultural Education.

Hoje estamos abrindo um novo modelo da nossa escola indígena e educação indígena Karajá, que está sendo construída por causa da pesquisa no Projeto Extraescolar e no Estágio, bem como a execução do trabalho no tema contextual. Tudo isso foi muito importante durante a realização da pesquisa. Por isso, realizei a pesquisa na aldeia com muita determinação, alegria e emoção, mesmo quando tive um momento de desespero e tristeza, por causa do falecimento de um membro importante da família, mas, com o apoio da comunidade e da minha família, estou fazendo este relatório geral da minha pesquisa. Então, este trabalho será dedicado para aqueles e aquelas que nos deixaram. Porque, antes da pesquisa final do meu avô, ele me ensinou a atividade masculina e eu aprendi, a fim de viver com a natureza, dentro da comunidade.

A ação da pesquisa ampliou o meu conhecimento sobre o que preciso na minha vida adulta, porque sem sabedoria e conhecimento não há vida no mundo. Por isso, me dediquei mais para fazer pesquisa sobre a minha cultura e minha língua para manter a vida com tantas sabedorias e conhecimentos da minha cultura. Para tal, escolhi os temas em diversas ocasiões.

Os conhecimentos e saberes que aprendi na comunidade são muito importantes para a futura geração do povo Karajá. Por exemplo: "Palavras Conectadas". Uma palavra vai se ampliando sem limites. Vejamos. WYHY é nome do objeto, que significa FLECHA, mas, quando se contextualiza, encontramos muitas palavras que são basicamente conectadas com ela, por exemplo: TÈ $\grave{E}, I U N I, T X U R \grave{A}$, $\grave{E S O \tilde{O}}$ TBÒRA, TBÒERÈ, TYTÉ. Além disso, as palavras vão se 
esticando, por exemplo: $A X I, D \grave{E B O ̀ N A, ~ U T U R A ~ R B U N A, ~ I R O D U ~}$ RBUNA, NAWII RBUNA, AÕRTI etc.

Assim, os saberes vão se expandindo, no cotidiano do povo Karajá. Por estes e outros fatores, hoje construímos o novo modelo de paradigma para a nossa escola e conhecemos novos modelos de ensino e aprendizagem. Por isso, é importante fazer a pesquisa: para conhecer o conhecimento sobre a cultura e a língua dentro da nossa própria comunidade.

Isto porque a pesquisa nos leva a contribuir para nossa cultura e língua serem registradas, ainda que vivamos com tantos impactos sociais e tecnologia. Entretanto, isso não tem importância para a nossa língua e cultura, como por exemplo, para crença, costumes, religião e tradição. Por isso, a ação da pesquisa é importante, porque a pesquisa me motivou a buscar o conhecimento milenar que existe na comunidade Karajá, para a cultura e a língua viverem para sempre com o nosso povo, mesmo que estejamos vivendo com outra cultura, que é a do não indígena, como o uso do aparelho celular, televisão, DVD, motocicleta, relógio e outros.

Desta maneira, os trabalhos foram muito importantes e com muita qualidade, no sentido de desenvolver as novas bases epistêmicas para a comunidade e a escola indígena Karajá se manifestarem. Exatamente por isso, este trabalho foi feito com interação entres membros da comunidade, escola, professores e alunos, para que possamos levar o conhecimento e que ele seja praticado em várias opções e, também, para os jovens e as crianças saberem o conhecimento da sua própria língua e cultura futuramente. Para tal, fazemos reuniões, palestras, seminários e outras atividades na aldeia. Isso é muito importante para todos e, por este motivo, a pesquisa é fundamental na comunidade Karajá.

Hoje, a pesquisa trouxe muitas capacitações por parte dos alunos e alunas e, também, na minha vida, para ser o professor da alfabetização, da cultura e língua Karajá. Aprendi muitas coisas através da pesquisa, como no Projeto Extraescolar. O tema contextual INY AHÃDUं ERYSYNA trouxe imenso conhecimento em relação à natureza, o que envolve a transformação que mostra os períodos de estações do ano para o povo Karajá, que são divididos em 05 partes.

Essas partes são: 1- BלेORA TMYRA, que tem suas representações específicas, por exemplo: Berira, Samosò, Bènorariòrèdi, Hãdoroosò, Rmasò, Ynanaòlò, Biudèlèixè, Bexu, Narù, bdolèèriorèdi etc.; 2- BÈÒA: nelas encontramos diversas 
ocasiões importantes: Hetohoky, Iibòò, Riu, Etehosò, Òwò, toxi e outros; 3- BEHTXI: não tem suas representações com vários nomes, mas ela representa as estações do ano que indicam que a água do rio fica estacionada e não enche e nem vasa; 4- WYRA TMYRA tem suas representações: Itxoduònoijsa, Notxienibèrèsè, Otxixabèrèsè, Òtuniòlòna, Oworutidyy, Bènoraderexi, Hãuteratyjyra, Rahasanoijsa, Dexiànoijsa, Juhtawèburètebure etc.; 5- WYRA, que tem suas representações assim: Ryijesy, Axi, Òtulòtihãtè, Biririòre, Samorarè, Raradòònoijsasò, Asidèriònoijsasò, heryrisò, Bdèradèrbu etc.

Então, todos estes conhecimentos são frutos do meu trabalho no Projeto Extraescolar, que vão ajudar na minha profissão como professor. Por isso, fico feliz de ter terminado este trabalho com o apoio da UFG, que me deu a oportunidade de realizar este movimento e atualizar os saberes Karajá na aldeia e registrar o conhecimento de vários aspectos importantes da língua, por exemplo, a palavra especializada hòò e outras palavras que são fundamentais para manterem vivas a cultura e a língua Karajá, de forma prática.

O que dei mais atenção, na pesquisa do Projeto Extraescolar, foi à escrita da língua Karajá, que me levou a estudar a prática de fazer escrita da língua Karajá com imenso prazer de exercitar. Porque, mesmo que eu seja falante da língua Karajá, eu pensava que sabia escrever a minha língua, mas, quando pratiquei, logo descobri que estava totalmente fora do padrão da escrita e, por isso, é tão importante pesquisar aquilo que não se sabe. Por isso, adoro fazer o Projeto Extraescolar, porque, através dele, aprendi a prática de escrever a minha própria língua Karajá. Com certeza, isso será marcante na minha vida.

No Estágio, dei mais atenção aos momentos em que os alunos e alunas interagiam com os temas e isso ajuda a minha capacitação como professor. Por este motivo, é importante que o tema seja pesquisado antes de lecionar, porque, se o professor leva um tema na sala de aula sem pesquisa, como ele vai aplicá-lo? Os alunos e alunas questionam e como será que ele vai responder? Assim, é importante pesquisar o que se deseja aplicar na sala de aula. Como no meu caso, pesquisei todos os temas trabalhados e abordei o caso.

Todos os alunos e alunas rapidamente interagiram e perguntaram sobre o tema aplicado durante a minha aula. Então, foi que notei que o Estágio realmente é formação de docente, mesmo que o tema seja intracultural ou intercultural. Também notei que todos nós somos intelectuais em alguns pontos, como no caso dos estudantes, embora 
tenham idades variadas. Portanto, o trabalho feito no Estágio envolveu muitos aprendizados, tanto para os estudantes, quanto para mim.

Isso foi uma conquista para mim, para os meus alunos e alunas, e para o povo Karajá, porque, atualmente, nós, como professores Karajá, devemos buscar o que nossos jovens e crianças precisam compreender sobre a cultura e a língua, para que se mantenham vivas dentro da escola e fora da escola. E também somos intelectuais para construir uma nova prática pedagógica, para que nossos alunos se tornem conhecedores e conhecedoras da sua própria cultura e língua. Por isso, a realização da pesquisa é muito importante. Vejo que o resultado da pesquisa cada vez mais está se ampliando para atender às demandas da comunidade Karajá.

O trabalho e o resultado da pesquisa devem atuar na aldeia. Por exemplo, no Estágio de 1 até o final, foram desenvolvidos vários temas importantes. Trabalhei sobre o Rio Araguaia e foi importante pesquisar e levar isto para sala de aula, devido à importância que o rio tem para o povo Karajá. O meu objetivo foi conquistado em algum ponto, mas, mesmo assim, vou continuar pesquisando, escrevendo e interrogando os sábios da comunidade na aldeia, para que o meu conhecimento seja ampliado e eu aprenda mais sobre o que não conheço dentro do Rio Araguaia.

E aquilo que foi pesquisado nunca vou esquecer na minha vida e profissão. Sempre ficará na minha memória. Por isso a pesquisa é importante, porque ela nos leva a nos aventurar e viajar no mundo do passado e chegar nos tempos de hoje.

Tudo que aprendi na vida sempre vale, porque só assim o conhecimento se torna uma nova fase da vida e o que eu sinto hoje se deu através da pesquisa. O projeto Extraescolar e o Estágio são referências da minha cultura, língua, escola e aldeia, porque vejo que muitas articulações das culturas e línguas estão presentes atualmente na escola e na comunidade.

Estes temas trouxeram uma nova concepção do olhar na cultura e na língua e resgatam a cultura, a língua e outras ocasiões interessantes a permanecer na vida do povo Karajá. Neste sentido, na minha concepção, todos os temas geraram alto nível de ensinamento para todos e, por isso, o Projeto Extraescolar e o Estágio são referenciais. A pesquisa foi desenvolvida na aldeia com o objetivo de resgatar a cultura que está em risco de desaparecer e também de fortalecer e atualizar a língua e a cultura do povo Karajá, porque sem cultura e língua nós não somos ninguém. 
Deste modo, é importante lembrar que tudo que está em nossa volta, no nosso cotidiano, é fonte de nossa vida. Como, por exemplo, o ciclo da natureza, que envolve a formação de diversas orientações da nossa vida na aldeia. Para isso, temos que preservar a natureza e sabemos que sem natureza nós não teremos nossa vida, língua e cultura. Por esse motivo, é tão importante fazer pesquisa na aldeia, com a própria língua, com os conhecimentos próprios e própria sabedoria.

Então, neste caso, a pesquisa foi uma conquista em algum ponto, mas mesmo assim podemos pesquisar mais na aldeia, para que nossos costumes, cultura, língua, crença e tradição sejam renovados para a futura geração do povo Karajá. Até porque, nos últimos anos, realmente a cultura e a língua gritavam por socorro, mas agora, através da pesquisa, conquistamos e resgatamos diversas atividades na cultura, língua e outros. Mas vale lembrar que isso foi através da pesquisa na aldeia com as anciãs e os anciãos.

Porém, é importante fazer a pesquisa enquanto nossos sábios da aldeia ainda estão com vida, porque, se a pesquisa demora, com certeza muitos conhecimentos vão embora junto com os mestres dos saberes locais. Por isso, vamos pesquisar sem esperar nada, porque somos esperanças de um povo. Somos articuladores dessas pessoas que vivem na aldeia. Somos defensores da própria cultura e língua.

Vamos adiante. Vamos pesquisar o que ainda falta na aldeia, para que possamos ser um povo alegre, forte na cultura e na língua. Hoje estou feliz por estar fazendo este relatório, porque nele não só apenas escrevo o que estou escrevendo, mas aqui tem a herança que os nossos ancestrais viviam com elas. Então, nesse caso, o relatório é resultado do trabalho que foi alcançado para reforçar a cultura e a língua, através da pesquisa.

Por isso, gostei muito de fazer pesquisa na minha comunidade, na minha própria língua e conhecimento próprio, para que seja renovado na vida do povo Karajá. E, também, gostei de fazer as entrevistas com a anciã, porque talvez isso ajude a relembrar tudo que existe na vida dela.

Portanto, dedico este relatório à minha professora tradicional. Ela se chama Celina Kosi Karajá e mora na aldeia Ibutuna-Tocantins. Ela me ensinou muita coisa em relação à cultura e à língua e ela também ampliou meu conhecimento sobre a comunidade Karajá. E, por outro lado, quem me ensinou também, foi a professora de língua portuguesa que se chama Maria do Socorro Pimentel da Silva. Às comunidades Karajá da aldeia Ibutuna; aos meus tios, que 
me ajudaram a fazer o meu trabalho de pesquisa. Dedico, também, ao meu pai, Hariana Karajá, e minha mãe Imahiki Karajá, que me motivaram a fazer a pesquisa.

Finalizo, aqui, o relatório com muita emoção, alegre, cheio de conquista e aprendizagem. Espero que meu estudo seja continuado na UFG.

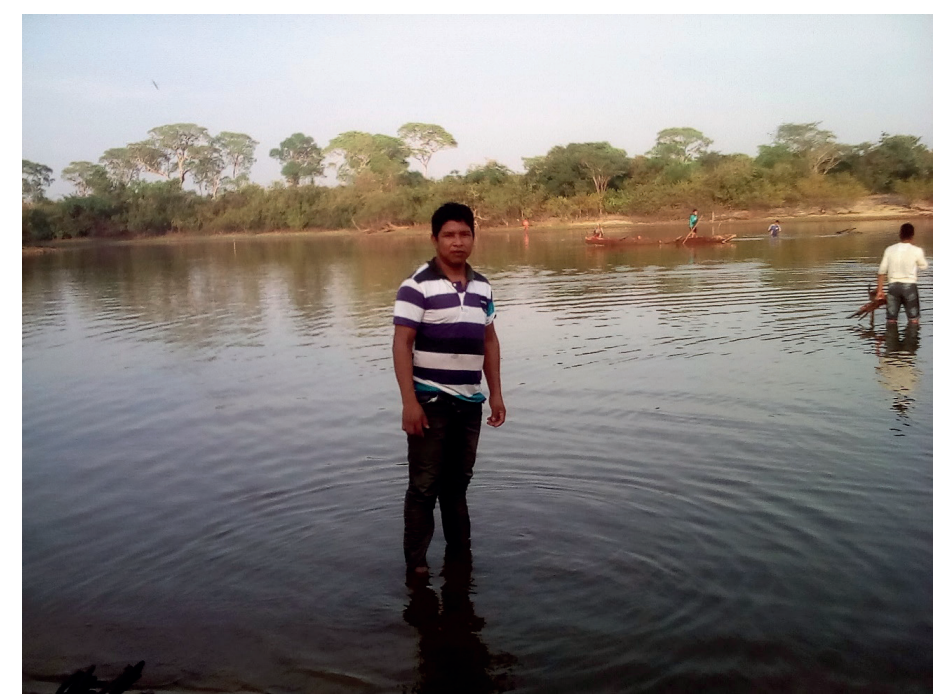

Axibdèdyyna

Inybdedyynanahekaawirare, tai sowemy aõwiwiraerymyhyre. Kaaaxi ki reri, ijoi mahadu wnaijoiraaxinyreahuki.

Tai ijõdire

\begin{tabular}{|l|l|l|}
\hline Uturaboho & - & Peixes \\
\hline Òwòrù & - & Árvore \\
\hline Bèè & - & Água \\
\hline Òraradè & - & Plantas \\
\hline Òrera & - & Jacaré \\
\hline Nawii & - & Pássaro \\
\hline Subruru & - & Lama \\
\hline
\end{tabular}



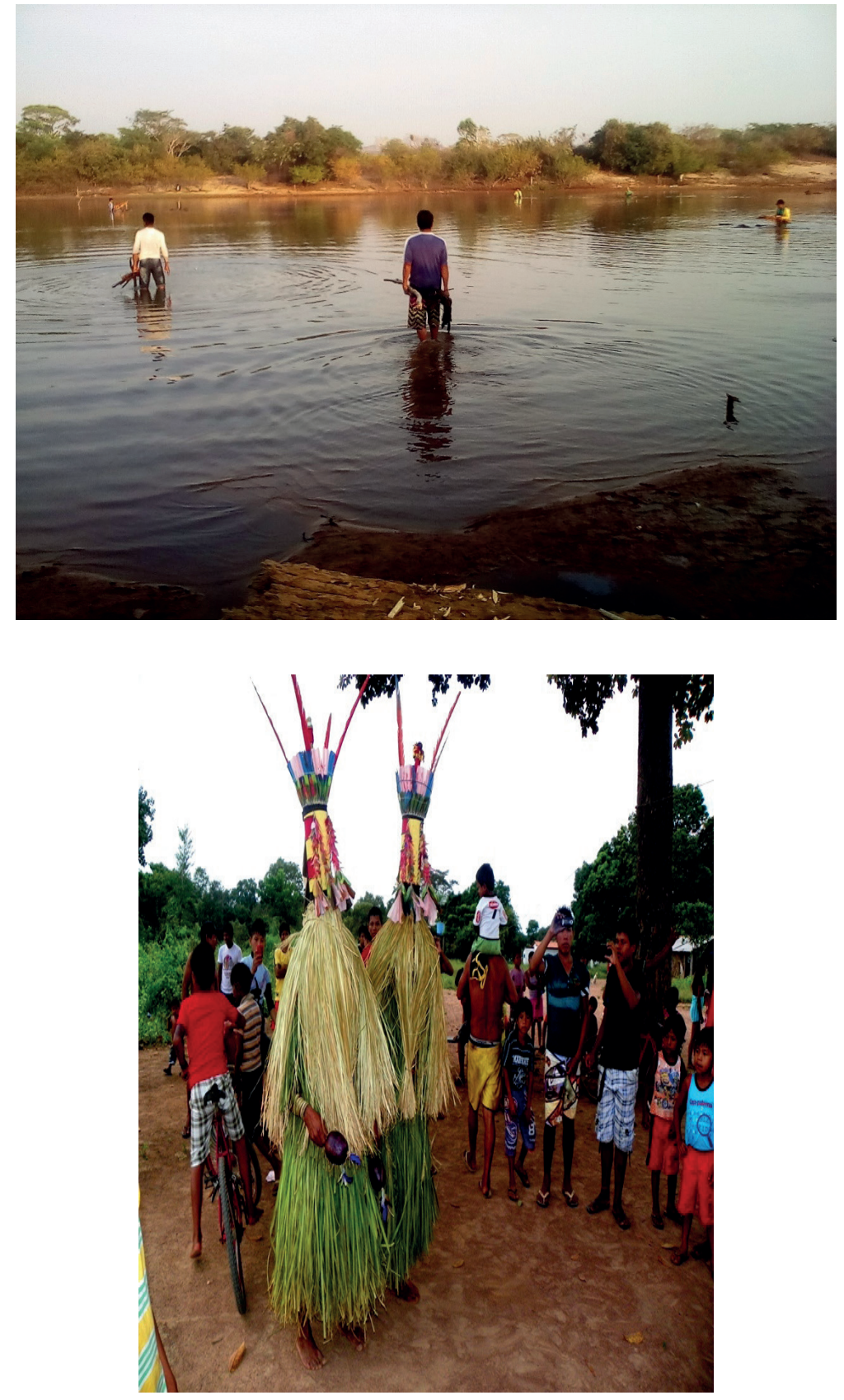

Ijasòtmyrahèkadeysananihiãrare - 

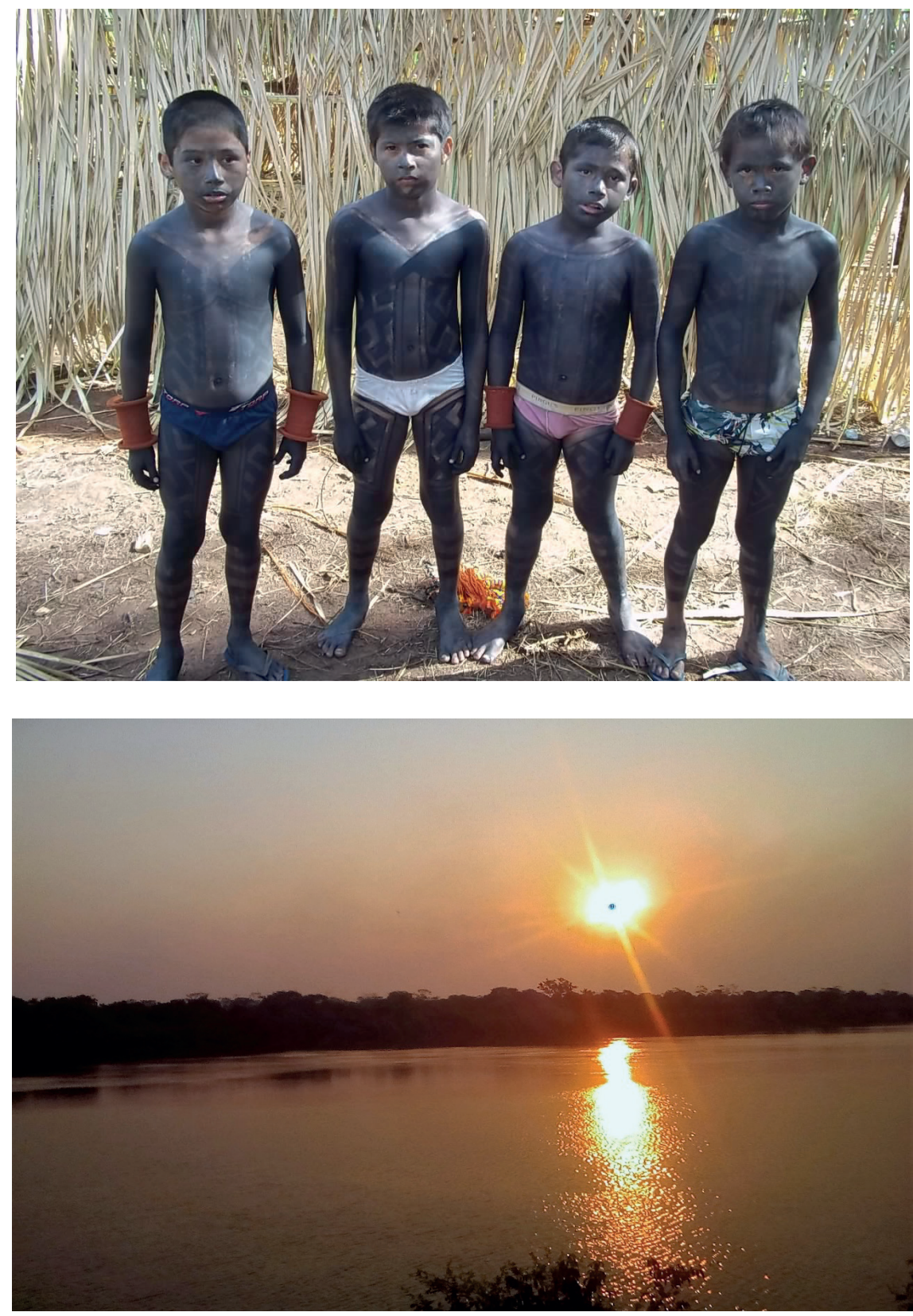


\section{REFERÊNCIAS}

PIMENTEL DA SILVA, M. S. Políticas Linguísticas no Estágio e nos Projetos Extraescolares. Goiânia: UFG, 2010.

PIMENTEL DA SILVA, M. S. Estágio e projetos extraescolares: uma articulação necessária na construção de práticas pedagógicas. Goiânia: UFG, 2010. 